\title{
Subversões do desejo: sobre gênero e subjetividade em Judith Butler ${ }^{*}$
}

\author{
Márcia Arán** \\ Carlos Augusto Peixoto Júnior***
}

\begin{abstract}
Resumo
A partir da sugestão de Judith Butler de que o gênero é uma norma, ou seja, uma construção social histórica e contingente, o presente trabalho procura fazer uma análise crítica dos conceitos de identificação e sexuação na psicanálise, oriundos de uma concepção estruturalista do sujeito e da diferença sexual. Parte-se do princípio de que, embora gênero e subjetivação sejam reiterações da norma sexual, na própria instabilidade da repetição do mesmo é possível vislumbrar a positividade da subjetivação como resistência, singularidade e produção de diferença.
\end{abstract}

Palavras-chave: Gênero, Sexualidade, Desejo, Subjetividade.

\footnotetext{
* Recebido para publicação em fevereiro de 2007, aceito em abril de 2007.

*** Professora Visitante do Instituto de Medicina Social, Universidade do Estado do Rio de Janeiro/UERJ. marciaaran@terra.com.br

***** Professor do Programa de Pós-graduação em Psicologia Clínica da Pontifícia Universidade Católica do Rio de Janeiro/PUC-RJ. cpeixotojr@terra.com.br.
} 
Subversões do desejo

Subversions of Desire:

on Gender and Subjectivity in Judith Butler

\begin{abstract}
From Judith Butler's suggestion that gender is a norm, that is, a historical and contingent social construction, this work intends a critical analysis of the concepts of identification and sexuation in psychoanalysis, derived from a structuralist conception of the subject and the sexual difference. We start from the principle that even if gender and subjectivation are reiterations of the sexual norm, in the instability itself of the repetition of the same it is possible to glimpse the positivity of the subjectivation as resistance, singularity and production of difference.
\end{abstract}

Keywords: Gender, Sexuality, Desire, Subjectivity. 
Márcia Arán e Carlos Augusto Peixoto

Não é de hoje que Judith Butler vem trabalhando de forma rigorosa temas como gênero, sexualidade, poder e subjetividade. Desde um de seus primeiros livros, intitulado Sujeitos do desejo (Butler, 1999), que a autora vem levantando questões extremamente importantes neste campo. Se lá ela se apropriava do pensamento francês contemporâneo para colocar certos problemas a propósito das relações entre desejo e subjetividade, nos trabalhos subseqüentes sua abordagem crítica de temas como gênero, identidade e diferença sexual foi se tornando cada vez mais incisiva. Com isso foram se radicalizando também suas críticas a uma certa ortodoxia psicanalítica, principalmente lacaniana, que, centrada na primazia do simbólico do édipo e da castração, acabou por restringir cada vez mais a abordagem dos processos de subjetivação a dicotomias opositivas binárias, evidentemente fundadas no poder coercitivo dos referentes transcendentes com sua pretensão de universalidade.

Neste artigo, portanto, aproveitamos algumas de suas reflexões sobre esses temas para avançar um pouco mais nas críticas a esta tradição psicanalítica que, insistindo em ignorar questões como a multiplicidade da diferença, a singularidade e as contingências sócio-históricas da subjetivação, acabou perdendo grande parte do seu potencial subversivo de questionamento. Assim, partindo de um problematização a respeito da normatividade própria às matrizes de gênero, que se impuseram desde a modernidade, procuramos em seguida formular uma crítica à concepção de simbólico fundada no estruturalismo, buscando alternativas de análise dos processos de subjetivação que contemplem formas de existência nos domínios do desejo e da sexualidade até então consideradas impossíveis de serem abordadas. 
Subversões do desejo

\section{A contingência das normas de gênero}

No texto "Regulações de gênero", Judith Butler (2006: 5773) considera que vários trabalhos realizados no campo dos estudos feministas ou dos estudos de gays e lésbicas partem do pressuposto de que o gênero é uma forma de regulação social. Dispositivos específicos de regulação - legais, institucionais, militares, educacionais, sociais, psicológicos e psiquiátricos - são evocados no intuito de refletir sobre a maneira pela qual tais regulações são engendradas e impostas aos sujeitos. Em geral, tende-se a pensar que existe uma separação entre o poder da regulação - entendido como uma estrutura unificada e autônoma - e o próprio gênero, como se o primeiro agisse reprimindo $e$ moldando os sujeitos sexuados, transformando-os em masculinos ou femininos. No entanto, para a autora, o problema é mais sutil. Não haveria uma regulação anterior ou autônoma em relação ao gênero, pois, ao contrário, o sujeito gendrado só passa a existir na medida de sua própria sujeição às regulações (Butler, 1997:1-31).

Esta concepção deriva fundamentalmente da teoria de poder formulada por Michel Foucault, na qual o poder não atua simplesmente oprimindo ou dominando as subjetividades, mas opera de forma imediata na sua construção. Assim, o caráter formativo ou produtivo do poder estaria totalmente vinculado aos mecanismos de regulação e disciplina que ele instaura e procura conservar (Peixoto Júnior, 2004). O que faz com que os discursos reguladores que formam o sujeito do gênero sejam os mesmos responsáveis pela produção da sujeição.

Com efeito, ao propor uma analítica do poder, Foucault considera que a partir da era moderna, o poder não pode mais ser tomado como um fenômeno de dominação maciço e hegemônico de um indivíduo sobre os outros ou de um grupo sobre os outros, tal como se pode constatar no modelo da Soberania. O poder problematizado como biopoder seria, antes, algo que circula, que funciona em rede, fazendo com que o indivíduo não seja o outro do poder, mas um dos seus primeiros efeitos. A principal forma de 
Márcia Arán e Carlos Augusto Peixoto

exercício do poder, que aparece na passagem do séc. XVIII para o século XIX, é a do regime disciplinar, o qual produz um discurso que não é o da lei ou da regra jurídica, mas aquele das ciências humanas que se constituirá enquanto norma (Foucault, 1992:183). Esta normatividade opera de forma imanente às práticas históricas e sociais, produzindo efeitos duradouros de territorialização no campo subjetivo. Atuando como ideal regulador, ela estabelece fronteiras entre determinadas práticas tidas como inteligíveis, lícitas e reconhecíveis e outras consideradas ininteligíveis, ilícitas e abjetas, as quais constituem o território dos anormais (Foucault, 1999).

Porém, diferentemente de Foucault, Butler considera que as regulações de gênero não são apenas mais um exemplo das formas de regulamentação de um poder mais extenso, mas constituem uma modalidade de regulação específica que tem efeitos constitutivos sobre a subjetividade. As regras que governam a identidade inteligível são parcialmente estruturadas a partir de uma matriz que estabelece a um só tempo uma hierarquia entre masculino e feminino e uma heterossexualidade compulsória. Nestes termos o gênero não é nem a expressão de uma essência interna, nem mesmo um simples artefato de uma construção social. O sujeito gendrado seria, antes, o resultado de repetições constitutivas que impõem efeitos substancializantes. Com base nestas definições, a autora chega a afirmar que o gênero é ele próprio uma norma (Butler, 2006:58).

Sujeitado ao gênero, mas subjetivado pelo gênero, o "eu" nem precede, nem segue o processo dessa "criação de um gênero", mas apenas emerge no âmbito e como a matriz das relações de gênero propriamente ditas (Butler, 1993:7).

Um dos exemplos mais notáveis da naturalização dos processos de construção da identidade decorrentes da repetição das normas constitutivas seria a interpelação médica. Nesse caso, através do procedimento da ultra-sonografia, transforma-se o 
Subversões do desejo

"bebê" antes mesmo de nascer em "ele" ou "ela", na medida em que se torna possível um enunciado performativo do tipo: "é uma menina"! A partir desta nomeação, a menina é "feminizada" e, com isso, inserida nos domínios inteligíveis da linguagem e do parentesco através da determinação de seu sexo. Entretanto, essa "feminização" da menina não adquire uma significação estável e permanente. Ao contrário, essa interpelação terá que ser reiterada através do tempo com o intuito de reforçar esse efeito naturalizante. Certamente seria estranho, diante da imagem de um bebê numa ultra-sonografia, afirmar que "se trata de uma lésbica". Como este enunciado não faz parte de nossa inteligibilidade cultural, ele serve antes de tudo para demonstrar de maneira muito precisa como o ato de nomear é, ao mesmo tempo, a repetição de uma norma e o estabelecimento de uma fronteira.

Dessa forma, a nomeação do sexo é um ato performativo de dominação e coerção que institui uma realidade social através da construção de uma percepção da corporeidade bastante específica. A partir dessa perspectiva pode-se entender que o gênero é uma "identidade tenuamente construída através do tempo" por meio de uma repetição incorporada através de gestos, movimentos e estilos (Butler, 2003:200).

Porém, se os atributos de gênero são performativos e não uma identidade pré-existente, a postulação de um "verdadeiro sexo" (Foucault, 1994) ou de uma "verdade sobre o gênero" revela antes uma ficção reguladora. Além disso, se para que essa ficção permaneça é necessário uma repetição reiterativa, podemos pensar que a aproximação de um ideal de gênero - masculino ou feminino - nunca é de fato completa, e que os corpos nunca obedecem totalmente às normas pelas quais sua materialização é fabricada. Nesse sentido, é justamente pelo fato de a instabilidade das normas gênero estarem abertas à necessidade de repetição do mesmo que a lei reguladora pode ser reaproveitada numa repetição diferencial. Assim, afirma Butler: 
Márcia Arán e Carlos Augusto Peixoto

O gênero é o mecanismo pelo quais as noções de masculino $e$ feminino são produzidas e naturalizadas, mas ele poderia ser muito bem o dispositivo pelo qual estes termos são decontruídos e desnaturalizados (Butler, 2006:59).

Essa tensão paradoxal permite compreender que se o gênero é uma norma, ele também pode ser fonte de resistência.

Mais uma vez é com Foucault que podemos nos aproximar da hipótese formulada por Butler sobre a contingência das normas de gênero. Em "Sujeito e poder", Foucault (1995) procura desenvolver e aprofundar como exatamente se constituem as relações de poder implicadas na produção de subjetividades. $\mathrm{O}$ que se destaca de sua análise é mais precisamente este aspecto: na própria engrenagem do poder estaria implicada uma força de resistência com um notável potencial de transformação. Para o autor, no centro das relações de poder, agindo como condição imanente de sua possibilidade, há uma "insubmissão" constitutiva que permite uma inversão eventual das estratégias empregadas nesse diagrama de forças. Poder e resistência constituem assim, reciprocamente, "uma espécie de limite permanente de ponte de inversão possível" (Id. ib.:248). Como se pode notar, é justamente essa co-participação indissolúvel que impede a redução das múltiplas forças em jogo nesse campo a um modelo de poder negativo no que diz respeito às lutas libertárias. É importante reafirmar que, para Foucault, o poder tem um caráter positivo $e$ produtivo. Dessa forma, não seria fundamentalmente contra o poder que nascem as possibilidades de resistência, seja ela singular ou coletiva, mas contra certos efeitos de poder num espaço paradoxalmente aberto na própria estratégia de sua constituição.

Se o gênero é uma norma, não podemos deixar de lembrar o que há de frágil na sua incorporação pelas subjetividades. Há sempre uma possibilidade de deslocamento que é inerente à repetição do binarismo masculino-feminino. Não é à toa que, 
Subversões do desejo

como afirma Butler, expressões tais como "problemas de Gênero", "gender blending", "transgêneros" e "cross-gender" já sugerem o ultrapassamento deste binarismo naturalizado (Butler, 2006:60).

Ainda assim, para formular uma nova concepção de subjetivação que acompanhe a reelaboração das normas de gênero, é importante salientar a diferença entre uma interpretação estruturalista da subjetividade - que pressupõe a permanência da hierarquia, do binarismo, da heterossexualidade e da diferença sexual como condição da cultura -, e uma concepção histórica $e$ contingente, que permita pressupor a ultrapassagem subversiva dessas fronteiras normativas. Mesmo que se queira mantê-las numa relação de tensão, é importante não perder de vista a necessidade de uma leitura crítica mais apurada dos pontos de vista sobre gênero e desejo fundados numa perspectiva estrutural.

\section{A crítica ao simbólico estruturalista}

No debate sobre política, sexualidade e novas formas de subjetivação na cultura contemporânea tem sido recorrente a utilização da categoria de simbólico como estratégia política de sedimentação do campo social. No âmbito da psicanálise, alguns teóricos de inspiração lacaniana, herdeiros do estruturalismo de Claude Lévi-Strauss, sustentam que as normas de gênero não seriam apenas construções histórico-sociais e, nesse sentido, contingentes, mas "posições" ditas sexuadas que necessariamente ocupam um lugar pré-determinado pelo simbólico. Um excelente exemplo desse embate político pode ser encontrado no debate ocorrido na França por ocasião da aprovação do "Pacto Civil de Solidariedade (Pacte Civil de Solidarité, Pacs ${ }^{1}$ ), em 1999, que colocou na ordem do dia a necessidade de uma problematização das noções de diferença sexual, parentesco e filiação. Neste

1 "Pacto civil de solidariedade que pode ser concluído por duas pessoas físicas, independentemente do seu sexo para organizar sua vida comum". 
Márcia Arán e Carlos Augusto Peixoto

debate, não foram os argumentos biológicos ou psicológicos, mesmo os mais comuns, que serviram de base para a argumentação político-científica contra o casamento homossexual, e sim aqueles que falavam da necessidade de uma "preservação simbólica" da sociedade e da cultura (Arán, 2005). Tal argumentação fundava-se na hipótese de que mudanças na maneira de se conceber a diferença entre os sexos nos levaria a uma suposta "dessimbolização" cultural, provocada por uma política de "indiferenciação", resultante do "apagamento da inscrição da diferença sexual no simbólico" (Borrillo e Fassin, 2001). Neste sentido, com o objetivo de preservar "o simbólico", a tríade heterossexualidade-casamento-filiação foi de imediato evocada como guardiã da sociabilidade, fazendo do casamento homossexual algo impensável e, conseqüentemente, indesejável.

Uma das teses mais insistentemente defendidas nesta ocasião partia da polêmica afirmação de Françoise Héritier, considerada uma das principais seguidoras de Lévi-Strauss, de que "nenhuma sociedade admite o parentesco homossexual", ou ainda, de que "pensar é antes de tudo classificar, classificar, é antes de tudo discriminar, e a discriminação fundamental é baseada na diferença de sexos" (apud Id. ib.:106). Com efeito, em seu livro Masculin/féminin. La pensée de la différence (Héritier, 1996), analisando as relações de parentesco, aliança, divisão sexual do trabalho $e$ as representações sobre fecundação em diversas culturas, a autora afirma que a observação primeira da diferença entre os sexos funda a estrutura do pensamento. Nessas condições, o corpo humano como lugar privilegiado de observação, principalmente na sua função reprodutiva, daria suporte a uma oposição conceitual essencial: aquela que opõe a identidade à diferença. Assim, Héritier considera que a própria estrutura do pensamento é construída a partir de um sistema hierárquico que se constitui por categorias binárias.

Seguindo essa linha de raciocínio, certa interpretação do pensamento psicanalítico, derivada da concepção estruturalista da sociabilidade evocada neste debate, faz dos complexos de Édipo e 
Subversões do desejo

de castração uma matriz normativa para a sexualidade. Nesse caso, o "primado genital", travestido de "simbólico", torna-se o telos em relação ao qual a homossexualidade só pode ser pensada como narcisismo ou perversão. Porém, mais do que apenas refletir sobre as relações de parentesco, a psicanálise lacaniana acabou por atribuir a esta concepção da sociabilidade o estatuto de fundamento originário da linguagem e da própria subjetividade. A partir da recuperação da tese da lei da interdição do incesto como fundamento da cultura, Lacan foi levado a descrever o recalque primário como fundador do sujeito do inconsciente. Com isso, ficaria do lado de fora, como exterioridade inacessível, a Coisa materna, que só se faria presente como nostalgia de um objeto para sempre perdido. A lei do pai, força constitutiva do recalque originário, operador transcendente do processo de subjetivação, faria do desejo humano uma incondicionalidade que tende a afirmar-se a qualquer preço. Essa "passagem para a cultura" será elaborada detalhadamente na formulação dos três tempos do Édipo estrutural, onde o autor procura demonstrar como a mesma lei responsável pela a interdição do incesto fará da diferença sexual a causa significante do desejo (Arán, 2005). Muitos psicanalistas argumentam que é impossível prescindir da centralidade dos conceitos de castração e de simbólico para abordar os processos de subjetivação, talvez pelo fato de que para muitos deles se encontre aí a única possibilidade de pensar a alteridade. ${ }^{2}$ Mas seria realmente esta a alternativa que nos resta ou ainda seria possivel pensar de maneira diferente em psicanálise?

Para melhor compreender esse tipo de aproximação entre cultura, subjetividade e heterossexualidade, vale a pena recuperar de forma sucinta a sua configuração básica em Freud e Lacan. Segundo o vocabulário de Laplanche e Pontalis o complexo de castração é:

2 Para uma análise crítica destes pressupostos, ver Arán, 2001. 
Márcia Arán e Carlos Augusto Peixoto

...o complexo centrado na fantasia de castração, que vem trazer uma resposta ao enigma da diferença de sexos (presença ou ausência de pênis): esta diferença é atribuída a um corte do pênis da criança do sexo feminino... A estrutura $e$ os efeitos do complexo de castração são diferentes no rapaz e na menina. O rapaz teme a castração como realização de uma ameaça paterna em resposta às atividades sexuais, do que lhe advém uma intensa angústia de castração. Na menina, a ausência de pênis é sentida como dano sofrido que ela procura negar, compensar ou reparar... O complexo de castração está em estreita relação com o complexo de Édipo, e mais especialmente com a sua função interditora e normativa (Laplanche \& Pontalis, 1983:111).

Nesta breve passagem, podemos observar como esta tese está fortemente relacionada à primazia do masculino. Com efeito, desde Freud, a teoria psicanalítica oficial oscila entre a tentativa de descrever a sexualidade feminina a partir da dialética do ter ou não o pênis-falo - onde necessariamente a mulher só pode ser concebida como um sujeito marcado por sua inferioridade - $e$ a suposição de que a mulher não existe (Arán, 2001).

Porém, a angústia de castração também foi associada por Freud a um conjunto de experiências traumatizantes de perda de um objeto investido de forma narcísica: perda do pênis, seio, fezes ou mesmo da criança durante o parto. Ainda assim, se essas experiências podem indicar outras formas de separação, o complexo de castração está diretamente relacionado à idéia de ameaça e punição, e só faz sentido quando associado ao caráter nuclear do complexo de Édipo. Dessa forma, na "ameaça de castração" que promove a proibição do incesto vem encarnar-se a função da "lei" enquanto instituinte da ordem humana. Momento em que, ao abandonar o investimento narcísico na mãe, a criança torna-se menino ou menina e passa necessariamente a desejar o outro sexo. Para Butler, essa operação de exclusão recíproca entre identificação e desejo resultante da proibição seria um dos 
Subversões do desejo

principais efeitos de reiteração da norma sexual reforçada pela psicanálise. A partir desta elaboração, a teoria lacaniana define a castração como uma operação simbólica que determina a estrutura subjetiva. Segundo Roland Chemama, para Lacan,

a castração se faz sobre o falo enquanto objeto não real, mas imaginário... A criança, menino ou menina, quer ser o falo para captar o desejo de sua mãe (é o primeiro tempo do Édipo). A interdição do incesto (o segundo tempo) deve desalojar-lhe desta posição de ideal do falo materno. Esta interdição provém do fato de que o pai simbólico, ou seja, uma lei, deve ser assegurado pelo discurso da mãe. Mas ela não visa somente a criança, ela visa igualmente a mãe $e$, por esta razão, ela é compreendida pela criança como sendo também castrada. No terceiro tempo intervém o pai real, aquele que tem o falo (mais exatamente, aquele que a criança supõe que o tenha), aquele que, em todo caso o usa e se faz preferir pela mãe. O menino que renunciou a ser o falo vai poder se identificar com o pai e ele terá então "no bolso os títulos necessários para se servir dele no futuro". Quanto à menina, este terceiro tempo lhe ensina para que lado ela deverá se voltar para ter o falo... (Chemama, 1993:39-40).

Mais uma vez, podemos constatar como a diferença sexual na psicanálise segue o modelo da dominação masculina caucionada na norma heterossexual. Cabe salientar que mesmo que haja uma diferença considerável entre as teorias formuladas por Freud e Lacan, nota-se que essa forma de subjetivação, ou mesmo de sociabilidade que resulta de uma castração estrutural, está totalmente adstrita a um dilema narcísico do sujeito, que acaba cedendo à lei do pai em função de uma ameaça à integridade do seu eu. Não que não existam fantasias de castração, mas, como afirma Michel Tort, essas fantasias são objeto de uma análise e não o seu objetivo. Ou seja, 
Márcia Arán e Carlos Augusto Peixoto

uma coisa é o conjunto de representações, que para os dois sexos, gravita em torno da castração, outra coisa é fazer da castração a natureza do processo de simbolização destas representações (Tort, 1990:10).

Isso quer dizer que a castração não pode servir sempre de modelo ou matriz universal que deverá moldar todas as subjetividades. Existem outras formas de simbolização, irredutíveis a essas pretensões totalizantes e totalitárias, as quais também só podem ser concebidas a partir de um outro referencial teórico.

Porém, o que importa destacar é que, para Lacan, o pai simbólico ou o Nome-do-pai é considerado uma instância irredutível às metamorfoses do social concernentes às figuras paternas reais e imaginárias. Se o pai imaginário pode vir a ser afetado de forma mais incisiva pelas contingências sóciohistóricas, sua função estrutural simbólica mostra-se praticamente imune a elas. Essas formulações teóricas permitem que o autor chegue a derivar daí uma diferença fundamental entre a heterossexualidade e a homossexualidade. Referindo-se à homossexualidade masculina, Lacan afirma que:

no momento em que a intervenção proibidora do pai deveria se identificar com o falo, o sujeito encontra na estrutura da mãe, ao contrário, o suporte, o reforço que faz com que esta crise não ocorra (Lacan, 1999:215).

Vale ressaltar ainda que, segundo Elisabeth Roudinesco (2003), Lacan, ao contrário de Freud, faz da homossexualidade uma perversão em si: não uma prática sexual perversa, mas a manifestação de um desejo perverso comum aos dois sexos. Assim, de acordo com o pensamento lacaniano, o homossexual seria uma espécie de perverso sublime da civilização obrigado a endossar a identidade infame a ele atribuída pelo discurso normativo. Nesse sentido, como notou Butler, para que a norma heterossexual permaneça intacta como uma forma social distinta, 
Subversões do desejo

ela exige a produção da homossexualidade como desvio, tornando-a culturalmente ininteligível (Butler, 203:116).

No entanto, não são poucos os trabalhos que demonstraram como o modelo tradicional, ao qual se recorre para pensar a diferença entre os sexos na psicanálise, é o modelo historicamente construído nos séculos XVIII e XIX - da hierarquia entre $\mathrm{o}$ masculino $e$ o feminino $e$ da exclusão da homossexualidade (Arán, 2001). Nesse sentido, levar em conta a historicidade do sexual não é apenas uma questão ética e política, mas, sobretudo, uma questão teórica da maior importância. Se existe um território sexual "fora" ou "excluído" do simbólico, em relação ao qual o próprio simbólico se constitui, é fundamental reconhecer como as contingências históricas e políticas podem promover neste mesmo território deslocamentos subjetivos, ampliando as possibilidades existenciais.

Não é difícil perceber que a fixidez da lei estruturalista estabelece as posições consideradas legítimas através da imposição de uma matriz heterossexual. Todo o resto, então, torna-se incompreensível, caso não corresponda a um esquema binário hierárquico, e permanece como um excesso impossível de ser inscrito no âmbito simbólico. Os conceitos de identificação $e$ sexuação na psicanálise estão de tal forma adstritos a uma lei estabelecida a priori, que acabam por fixar $e$ restringir as manifestações das sexualidades a duas posições normativas: "masculino" e "feminino":

Deve haver uma ligação entre esse processo de "assunção" de um sexo, a questão da identificação e os meios discursivos pelos quais o imperativo heterossexual capacita certas identificações de sexo e foraclui e/ou des-reconhece outras identificações (Butler, 1993:3).

Se compreendermos a lei como uma estrutura anterior $e$ transcendente às manifestações sociais, políticas $e$, necessariamente, históricas, o simbólico será apresentado como 
Márcia Arán e Carlos Augusto Peixoto

uma força que não poderá ser modificada e subvertida sem a ameaça da psicose ou da perversão. Ao contrário, se compreendermos a lei como algo que é vivido e constantemente reiterado de forma imanente às relações de poder, as possibilidades de modificação e subversão, inclusive do simbólico, não necessariamente significarão uma ameaça à cultura e à civilização (Arán, 2006; Peixoto Júnior, 2004a).

E preciso, portanto, um certo estremecimento dessas fronteiras excessivamente rígidas e fixas da identificação $e$ do desejo para que outras formas de construção do gênero possam habitar o mundo viável da sexuação e sair do espectro da abjeção.

A partir do que foi dito antes, podemos perceber como o registro simbólico tem se caracterizado como um limite às tentativas de reconfiguração das relações sociais. E, ainda, com um agravante: na medida em que os lacanianos elevam as estruturas de parentesco ao papel de operadores lingüísticos fundamentais, certas "posições" simbólicas são apresentadas como condição da própria linguagem. Porém, de acordo com Butler, o que o estruturalismo apresenta como "uma posição" na linguagem ou no parentesco não é a mesma coisa que uma norma. Como vimos anteriormente, a norma $e$ as relações de poder por serem produzidas socialmente são sempre suscetíveis a variações. Por isso, Butler procura mostrar

que a distinção entre a lei simbólica e a lei social não pode mais ser mantida, que o próprio simbólico é a sedimentação de práticas socais e que as alterações radicais do parentesco demandam uma reformulação dos pressupostos estruturalistas da psicanálise, já que nos levam a nos deslocar a um pós-estruturalismo queer da psique (Butler, 2006:62). 
Subversões do desejo

\section{Subjetividades queer}

Conforme acreditamos ter indicado, pressupor a instabilidade das normas de gênero permite afrouxar a relação entre a assunção do sexo e a escolha do objeto sexual. Nesse sentido, cabe perguntar o que acontece quando as proibições primárias contra $\mathrm{o}$ incesto produzem deslocamentos $e$ substituições que não se ajustam aos modelos supostamente normais da sexuação. Segundo Butler, na realidade, uma mulher pode encontrar o resíduo fantasmático de seu pai em outra mulher ou substituir seu desejo pela mãe por um homem e, neste momento, se produz um certo entrecruzamento de desejos heterossexuais e homossexuais. Se admitirmos a suposição psicanalítica de que as proibições primárias não apenas produzem desvios do desejo sexual, mas também consolidam um sentido psíquico de "sexo" e de diferença sexual, precisamos nos dar conta de uma conseqüência fundamental implícita neste ponto de vista. Daí parece decorrer que os desvios coerentemente heterossexualizados requerem que as identificações se efetuem sobre a base de corpos similarmente sexuados, e que o desejo se desvie através da divisão sexual para membros do sexo oposto. Mas, se um homem pode identificar-se com sua mãe e desejar partindo dessa identificação, de algum modo, ele já confundiu a descrição psíquica do desenvolvimento de gênero estável. E se esse mesmo homem deseja outro homem ou uma mulher, será que o seu desejo é homossexual, heterossexual ou mesmo lésbico? E o que significa restringir qualquer indivíduo dado a uma única identificação? (Butler, 1993:99).

Se tais fantasias podem saturar um lugar de desejo, não estamos em posição de ou bem nos identificarmos com um sexo dado, ou bem desejar alguém deste sexo; na realidade, de um modo mais geral, não estamos em posição de considerar que a identificação e o desejo sejam fenômenos reciprocamente excludentes. Identificar-se não é opor-se ao desejo, afirma Butler. A identificação é, ao mesmo tempo, uma trajetória fantasmática, 
Márcia Arán e Carlos Augusto Peixoto

uma resolução de desejo e uma assunção de lugar: trata-se da territorialização de um objeto que possibilita a identidade mediante a temporária resolução do desejo, que ainda permanece sendo um desejo, mesmo sob a sua forma repudiada.

A referência da autora à identificação múltipla não equivale a sugerir que todos se sintam compelidos a ser ou ter tal fluidez identificatória. A sexualidade é tão motivada pela fantasia de recuperar objetos perdidos quanto pelo desejo de permanecer protegido da ameaça de punição que tal recuperação poderia ocasionar. Também pode ocorrer que se estabeleçam certas identificações $e$ afiliações, certas conexões complacentes amplificadas, precisamente para instituir uma desidentificação com uma posição que pareça excessivamente saturada de dor e agressão, posição que, em conseqüência, só poderia ser ocupada imaginando-se conjuntamente a perda de uma identidade viável. As identificações, portanto, podem proteger contra certos desejos ou atuar como veículos para o desejo; para facilitar certos desejos talvez seja necessário proteger-se de outros: a identificação é o lugar no qual ocorrem, de modo ambivalente, a proibição e a produção do desejo (Peixoto Júnior, 2005).

Nesse contexto, a política queer torna-se emblemática, já que condensa em si tanto uma degradação passada como uma afirmação presente, demonstrando de forma radical a contingência das normas de gênero. A resignificação da sexualidade gay e lésbica através da abjeção e contra abjeção pôde significar uma proliferação e uma subversão do próprio simbólico, estendendo e alterando a normatividade dos seus termos. Ao introduzir as homossexualidades no terreno da simbolização, novas formas de subjetivação, assim como novas formas de sociabilidade, tornaram-se possíveis. Daí a necessidade de continuarmos a repensar os parâmetros a partir dos quais abordamos o desejo, a sexualidade e as subjetividades no mundo contemporâneo. Nesse sentido, a subversão do desejo também é uma abertura para novas possibilidades de existência até hoje consideradas impensáveis por certos autores. 
Subversões do desejo

\section{Referências bibliográficas}

ARÁN, Márcia. A Transexualidade e a gramática normativa do sistema sexo-gênero. Revista Ágora. Estudos em Teoria psicanalítica, vol. IX, $\mathrm{n}^{\circ} 1$, Rio de Janeiro, Editora da UFRJ, janeiro-junho, 2006, pp.29-63.

Políticas do desejo na atualidade; o reconhecimento social e jurídico do casal homossexual. Lugar Comum, Estudos de Mídia, Cultura e Democracia Homossexual, $\mathrm{n}^{\circ} \mathrm{s}$ 21-22, Rio de Janeiro, Editora da UFRJ, julho-dezembro, 2005, pp.73-90.

Sexualidade e política na cultura contemporânea: as uniões homossexuais. In: LOYLOLA, Maria Andréa. (org.) Bioética, reprodução e gênero na sociedade contemporânea. Rio de Janeiro/Brasilia, ABEP/Letras livres, 2005, pp.211-229.

O Avesso do Avesso: Feminilidade e novas formas de subjetivação. Tese de Doutorado, Saúde Coletiva, Instituto de Medicina Social da UERJ, 2001.

BoRRILLO, Daniel e FASSIN, Eric. Au-delà du PaCS. L'expertise familiale à l'épreuve de l'homosexualité. Paris, Puf, 2001.

BuTLER, Judith. Défaire le Genre. Paris, Éditions Amsterdam, 2006.

\section{Brasileira, 2003.}

Problemas de Gênero. Rio de Janeiro, Civilização

Subjects of desire: Hegelian reflections on twentieth-century France. New York, Columbia University Press, 1999.

The psychic life of power - theories in subjection. California, Stanford University Press, 1997.

Bodies that Matter. On the discursive limits of "sex". New York, Routledge, 1993.

Chemama, Roland. Dictionnaire de la Psychanalyse. Paris, Larousse, 1993.

FouCAUlt, Michel. Les anormaux, Cours au Collège de France (19741975). Paris, Gallimard, 1999.

Sujeito e poder. In: DREYFus, Hubert \& RABINOW, Paul. (orgs.) Michel Foucault Uma Trajetória Filosófica. Para além do estruturalismo e da hermenêutica. Rio de Janeiro, Forense Universitária, 1995, pp.231-249. 
Márcia Arán e Carlos Augusto Peixoto 1994.

Le vraie sexe [1980]. In: Dits et écrits IV. Paris, Gallimard,

. A Microfísica do Poder. Rio de Janeiro, Graal, 1992.

HÉRITIER, Françoise. Masculin/Féminin. La pensée de la différence. Paris, Editions Odile Jacob, 1996.

LACAN, Jacques. Seminário V. Formações do Inconsciente (1957-1958). Rio de Janeiro, Jorge Zahar Editor, 1999.

LAPLANCHE, Jean \& PONTALIS, Jean Baptiste. Vocabulário da Psicanálise. Rio de Janeiro, Martins Fontes, 1983.

PEIXOTO JÚNIOR, Carlos Augusto. Sexualidades em devir e subversão das identidades. Revista Ethica - cadernos acadêmicos, vol. 12, n's 1/2, Rio de Janeiro, UGF, 2005, pp.131-155.

Sujeição e singularidade nos processos de subjetivação. Revista Ágora - estudos em teoria psicanalítica, vol. VII, $\mathrm{n}^{\circ} 1$, Contracapa/UFRJ, 2004, pp.23-38.

- A Lei do desejo e o desejo produtivo: transgressão da ordem ou afirmação da diferença? Physis. Revista de Saúde Coletiva, vol. 14, $\mathrm{n}^{\circ}$ 1, Rio de Janeiro, IMS/UERJ/CEPESC, 2004a, pp.109127.

ROUDINESCO, Elisabeth. A Família em desordem. Rio de Janeiro, Jorge Zahar Editor, 2003.

TORT, Michel. Le Différend. Psychanalystes - Symboliser. Revue du Collège de Psychanalystes, n 33, Paris, 1990. 